\title{
sciendo
}

CIVIL AND ENVIRONMENTAL ENGINEERING REPORTS

E-ISSN 2450-8594

CEER 2019; 29 (3): 086-096

DOI: $10.2478 /$ ceer-2019-0026

Original Research Article

\section{INVESTIGATION ON ELECTRICALLY CONDUCTIVE AGGREGATES AS GROUNDING COMPOUND PRODUCED BY MARCONITE}

\author{
Mohd Yuhyi MOHD TADZA ${ }^{1}$, Tengku Hafidatul Husna TENGKU ANUAR, \\ Fadzil MAT YAHAYA \\ Faculty of Civil Engineering \& Earth Resources, Universiti Malaysia Pahang, \\ Lebuhraya Tun Razak, 26300 Gambang, Kuantan, Malaysia
}

\begin{abstract}
Marconite is often used as alternative material to improve the performance of earth grounding system. This study aims to investigate of the physical and mechanical behaviour of conductive aggregate derived from Marconite namely, the electrical resistivity, water absorption, and crushing strength. In addition, similar tests were also conducted on mortar aggregate for comparison. The resistivity of aggregates were measured using soil box method. Test results showed that the electrical resistivity, water absorption, and crushing strength of both aggregates varied with time. These values were found to be stabilised after approximately after 14 days. The electrical resistivity for aggregates containing Marconite were found to be $39.2 \Omega$.m, far lower than $12700 \Omega . \mathrm{m}$ obtained for mortar-based aggregates. Similarly, the water absorption for Marconite aggregates were greater compared to mortar aggregates. On the other hand, the crushing strength for Marconite aggregates was to be lower. Incorporating Marconite significantly improved the electrical resistivity behaviour while maintaining acceptable mechanical properties crucial for electrical grounding purposes.
\end{abstract}

Keywords: grounding system, conductive aggregate, marconite, ground enhancement material, resistivity

\footnotetext{
${ }^{1}$ Corresponding author: Faculty of Civil Engineering \& Earth Resources, Universiti Malaysia Pahang, Lebuhraya Tun Razak, 26300 Gambang, Kuantan, Malaysia, e-mail: dryuhyi@ump.edu.my, tel. +609-5492984
} 


\section{INTRODUCTION}

Earth grounding system serves as lightning-protection in industrial and power plants in order to distribute current during lightning strike [1]. A good grounding system should able to provide low resistant path while maintaining safe operation to power system and electrical components [2]. Soil resistivity varies with soil types, water content and temperature, porosity, size of grain particles and so on [3-4]. A new approach of using ground enhancement material was introduced to substitute unsuitable soil material in reducing the earth resistance due to cost and space limitation.

A good ground enhancement material should provide low earth resistance over a long period with little variation in the resistivity value [5]. Gomez [5] noted that the used of ground enhancement material as backfill material is the preferred the method in maintaining low resistance for a long period of time. Chung [6] found out that suitable grounding material is needed for tall buildings and other structures relating to electrical power. IEEE Std. 142, (2007) stated that, large substations, transmission line or generating stations should not exceed $1 \Omega$ in ground resistance while in range $1 \Omega$ to $5 \Omega$ for industrial plant substations, buildings and large commercial installations.

Electrically conductive component containing cement-based material is often used in reducing the resistivity due to its ability to bind conductive components to achieve stable and relatively small resistivity value [6]. Wu et al. [7] reported that concrete containing conductive materials in aggregated form increased the conductivity with value of resistivity of about $0.1 \Omega . \mathrm{m}$ to $0.3 \Omega$.m. However, these material display low compressive strength which is less than $25 \mathrm{MPa}$. Carbon fibre and carbon black were used as substitute materials for sand and aggregate with carbon fibre acts as good component to adjust electrically conductive concrete due to its high conductivity and tensile strength. Thus, when both materials were mixed together, high conductive performance with good mechanical properties were achieved [8]. Conductive concrete proves that it can be used as replacement materials where it can effectively decrease the grounding resistance.

Other studies showed that, incorporating steel fibre and graphite in cement matrix provide good mechanical property and improved resistivity [7]. Graphite was recommended as grounding materials due to its high carbon content, which can upgrade the conductivity of concrete [8]. Wang et al. [9] proposed the use of graphite in practice as conductive components. Addition of graphite resulted in good conductivity and low cost. Similarly, adding graphite to concrete will inevitably reduce the compressive strength, flexural strength and bending strength of the composite. Apart from graphite and carbon black, the use of Marconite has shown remarkable improvement in the resistivity value as grounding material 
[11]. Marconite is a granular material manufactured from coal and industrial byproduct that consists of carbon-based for consistency material [12]. As grounding material, Marconite is often used as backfill material or as sand replacement in concrete in aggregated form [13].

To date, information on the physical and mechanical properties of Marconite derived aggregates appears to be limited. In this study, Marconite is incorporated in cement mix to produce conductive aggregate is used as alternative grounding material. A semi-dry mixing method was adopted to disperse the Marconite within the cement matrix. The physical and mechanical properties were later determined and compared with mortar aggregates to identify the electrical resistivity, water absorption and crushing strength behaviours.

\section{EXPERIMENTAL STUDY}

\subsection{Selection of Raw Material}

Ordinary Portland cement (OPC) and sand were used in this study as the main materials to prepare the aggregates. Marconite acts as conductive material were initially mixed into the main materials to form conductive aggregates. Specific gravity and surface area for OPC are 3.15 and $3310 \mathrm{~cm}^{2} / \mathrm{g}$, respectively. The chemical compositions of OPC is presented in Table 1.

Table 1. Chemical composition of OPC used

\begin{tabular}{|c|c|}
\hline Chemical composition & OPC (wt. \%) \\
\hline $\mathrm{SiO}_{2}$ & 19.85 \\
\hline $\mathrm{Al}_{2} \mathrm{O}_{3}$ & 3.68 \\
\hline $\mathrm{CaO}$ & 65.14 \\
\hline $\mathrm{SO}_{4}$ & 5.40 \\
\hline $\mathrm{Fe}_{2} \mathrm{O}_{3}$ & 2.90 \\
\hline $\mathrm{MgO}$ & 1.78 \\
\hline $\mathrm{K}_{2} \mathrm{O}$ & 0.91 \\
\hline $\mathrm{TiO}_{2}$ & 0.27 \\
\hline $\mathrm{Na}_{2} \mathrm{O}$ & - \\
\hline
\end{tabular}

Marconite in granular form was purchased from Tokai Engineering Malaysia Sdn. Bhd. The specific gravity of Marconite used was about 1.36, whereas the surface area of Marconite was around $0.33 \mathrm{~m}^{2} / \mathrm{g}$.

\subsection{Preparation of aggregate}

Marconite was first crushed using a steel hammer passing $150 \mu \mathrm{m}$ sieve. The sample was then oven dried for 24 hours at temperature $105^{\circ} \mathrm{C}$. Later, the sample was kept in sealed plastic bag. The weight ratio of OPC to sand was fixed at 0.25 , 
while for water to solid material ratio was also fixed at 0.3 The electrically conductive aggregates were prepared by following the method described by Chen et al. [14]. Dry powder of OPC and sand were first mix in dry condition. During the mixing stage, one third of total water required to mix the OPC and sand at the semi-dry condition to improve the dispersion. With another two thirds of water was added gradually after 10 minutes to bind the fine particles. One litre of mixture was weighted to calculate the mass of conductive material to be added up in the mixing which is $1 \%$ by mass of total raw materials. After that, the conductive material, Marconite was added into the mixture and then mixed vigorously for five minutes to ensure the constant distribution of conductive component.

Two different series of mix formulations were considered. The first series of mix formulations were OPC and sand mixed with water without adding with carbonbased materials. Next, Marconite was added in the second series of formulations. The produced aggregates as shown in Fig. 1 were cured at room temperature for 7,14 and 28 days.

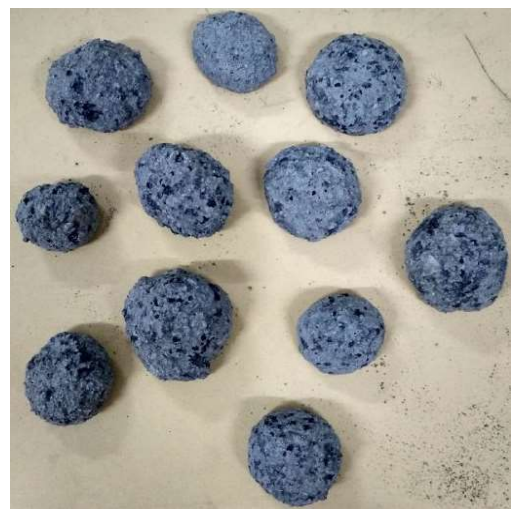

Fig. 1. Photo of manufactured electrically conductive aggregate

\subsection{Test method}

\subsubsection{Electrical resistivity test}

The aggregate prepared in Section 2.2 were carefully molded in a rectangular soil box apparatus for easy measurement, ensuring that the aggregates were placed as close as possible in order to achieve good contact between each other. Electrical resistivity of cement as the main binder will be directly affect the electrical resistivity of aggregates. The electrical resistivity for conductive aggregates were measured at different elapsed time of 7, 14 and 28 days after the curing process. The aggregates was first removed from water and gently rolled on a surface of 
dry tissues. Later, the aggregates was placed in a soil box. A four-point electrode (Wenner probe setup) techniques were employed to record the aggregate electrical resistance. A Tinker \& Rasor SR-2 resistivity meter was used for this purpose. Fig. 2 shows the soil box and resistivity meter used in this study.

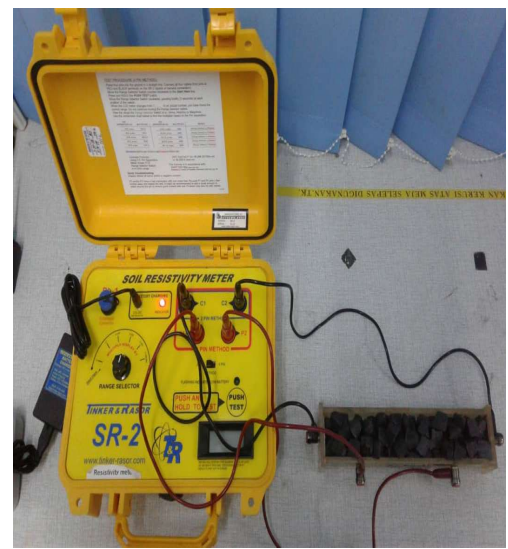

Fig. 2. Tinker \& Rasor resistivity meter with soilbox attachment

\subsubsection{Water absorption test}

The water absorption of aggregates was measured according to BS EN 1097-6 after 7,14 , and 28 day of curing process. The aggregates were removed from water and dried at temperature of $105^{\circ} \mathrm{C}$ until it reach the constant mass. With the same aggregates engrossed in water for 24 hour. Later, the aggregates were removed from water and dried by gently rolled on a piece of dry tissue. The water absorption of aggregates for 24 hour is calculated using the Eq. 2.1.

$$
W A_{24 h}=\frac{M_{s a t}-M_{d r y}}{M_{d r y}}
$$

where $M_{d r y}$ is the mass of the oven dry aggregates, and $M_{\text {sat }}$ is the mass of saturated aggregate after 24 hour.

\subsubsection{Crushing strength test}

The crushing strength of conductive aggregates was tested by uniaxial compression test between two parallel rigid plates. Aggregates had immersed in the water for curing process and performed the crushing strength at $7^{\text {th }}, 14^{\text {th }}$, and $28^{\text {th }}$ day. The aggregate was removed from the water, and dried on the surface by gentle rolling on the tissues and placed the aggregate at the centre of the plates. The load at fracture aggregate was recorded with the measured of aggregate. The crushing strength of each aggregate is calculated using Eq. 2.2. 


$$
S=\frac{2.8 P_{c}}{\pi X^{2}}
$$

where $P_{c}$ is the load at fracture and $X$ is the diameter of aggregate.

\section{RESULTS AND DISCUSSION}

\subsection{Electrical resistivity}

Figure 3 shows the electrical resistivity of aggregates prepared with mortar and Marconite with elapsed time. Based on the results, the electrical resistivity values are affected with time. The electrical resistivty for both aggregates were found to stabilised after a testing period of about 14 days. In the case of Marconite aggregate slight variation in the resistivity value. The resistivity of Marconite aggregate was found to be within 39.2 to $53.8 \Omega . \mathrm{m}$. However, increased in the electrical resistivity value was noted for mortar aggregate. Initially, after 7 days the electrical resistivity was $84.6 \Omega . \mathrm{m}$ for mortar and later increased to $12810 \Omega . \mathrm{m}$ and $12700 \Omega$.m for 14 and 28 days, respectively. As dry cement and sand have high resistivity values (i.e order of $10^{6} \Omega . \mathrm{m}$ ), the lowering of electrical resistivity initially is primarily due to the presence of water. Water act as bridging agent to conduct electricity within the cement-sand mixture. During hardening, water evaporated and increase the ability of current to flow through the mortar aggregates [1][8]. On the other hand, the presence of highly conductive Marconite maintained the electrical resistivity value of Marconite derived aggregate and water have less influence in determing the overall performance as grounding material [26].

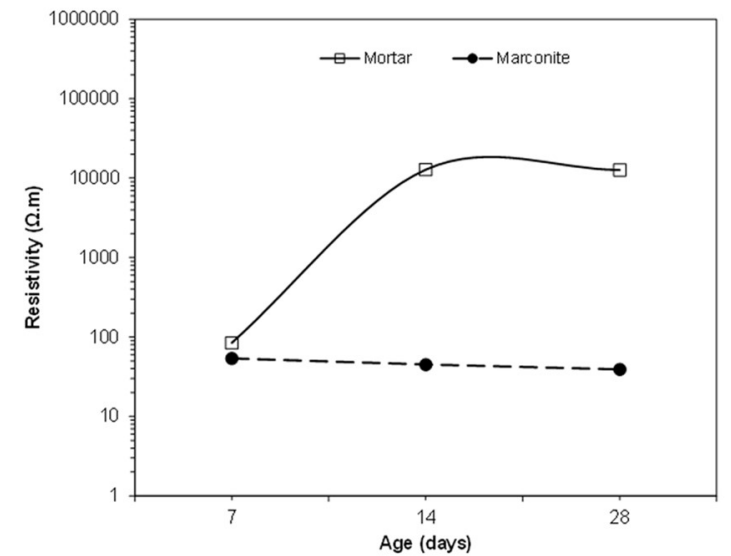

Fig. 3. Electrical resistivity of aggregate with mortar and Marconite 


\subsection{Water absorption}

The relationship between water absorption of mortar and Marconite aggregates and curing time is shown in Fig. 4. The resistivity evolution of concrete is affected by the curing regimes Presuel-Moreno et al. [15]. Referring to Fig. 4, it was noted that prolonged curing time resulted in increased water absorption for all aggreagates. The values for both aggregates were found to stabilised and remain somewhat unchanged after 14 days. In this case, Marconite aggregate remained at high level of water absorption compared to mortar aggregates. Marconite steadily increased from 9.14 to $13.22 \%$ for 7 and 14 days but little differ after 28 days curing to $12.93 \%$. In addition, the water absorption of mortar aggregates shows a slight increase in the water absorption from 7 to 28 days within 10.18 to $10.85 \%$. Similar to the lightweight aggregates in the the water absorption of Marconite is acceptable within the range of 9 to 13\% [16]. Similarly, Tuan et al. [17] proposed that, the water absorption of lightweight aggregates should be below $20 \%$ after 24 hour immersion. The water absorption with concrete mixture immersion is mainly influenced by the factors that governing concrete porosity [18]. In other words, presence of pores in Marconite aggreagate is greater. Isolated pores or vitrified surface tends to absorp little water while one with connected or open pores will absorb more water [19]. It was also suspected that the carbon derived Marconite caused agglomeration of carbon influence high porosity of aggregates [14]. Studies have shown that carbon has the ability to absorb water and retained ions, which contribute to the improvement ability of current to flow within the matrix [20]. Thus, produced conductive aggregates with presence of Marconite exhibit satisfactory water absorption compared to mortar aggregate. The avalability of higher water content in Marconite aggregate also enhanced the resistivity value as water film acts as bridging agent to allow more electrical current to flow.

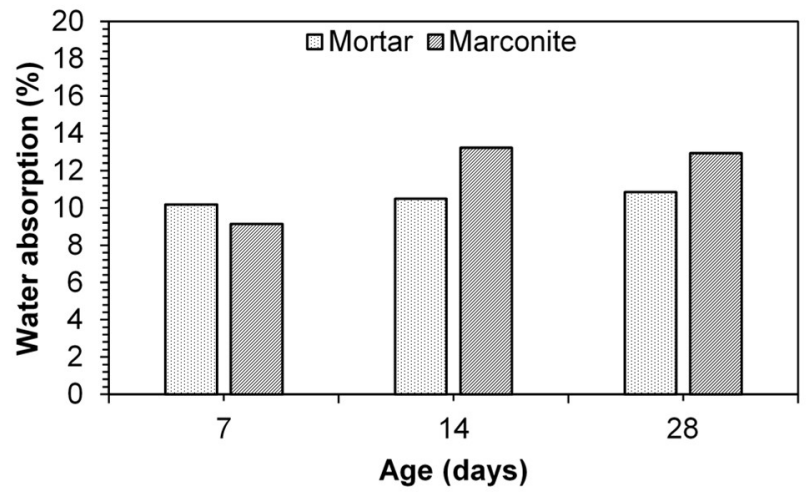

Fig. 4. Water absorption of aggregate with mortar and Marconite 


\subsection{Crushing strength}

Figure. 5 shows the crushing strength versus curing time for the mortar and Marconite aggregates. The crushing strength of aggregates are affected with time. The crushing strength for mortar and Marconite aggregates were increased consistently and stabilised after 28 days curing period. The crushing strength of Marconite aggregate increased slightly from 7.48 to $11.12 \mathrm{MPa}$. On the other hand, the crushing strength for mortar aggregate after 7 day was $9.20 \mathrm{MPa}$ and gradually increased to $10.24 \mathrm{MPa}$ and $11.75 \mathrm{MPa}$ for 14 and 28 days, respectively. Previous study have showed that, compressibility behavior of material incorporated with carbon generally is much lower [21]. González-Corrochano et al. [16] stated that the crushing strength of artificial lightweight aggregates should be above $0.5 \mathrm{MPa}$ when comparing to commercial lightweight aggregate. Concrete strength at a given age depends on the type and and characteristic mix proportion of the slag in the concrete [22]. Compressive strength is affected by interrelated factors, for instance, pore size and distribution, shape of aggregates, and effects due sintering that can enhance the porosity and strength while reducing water absorption [23-24].

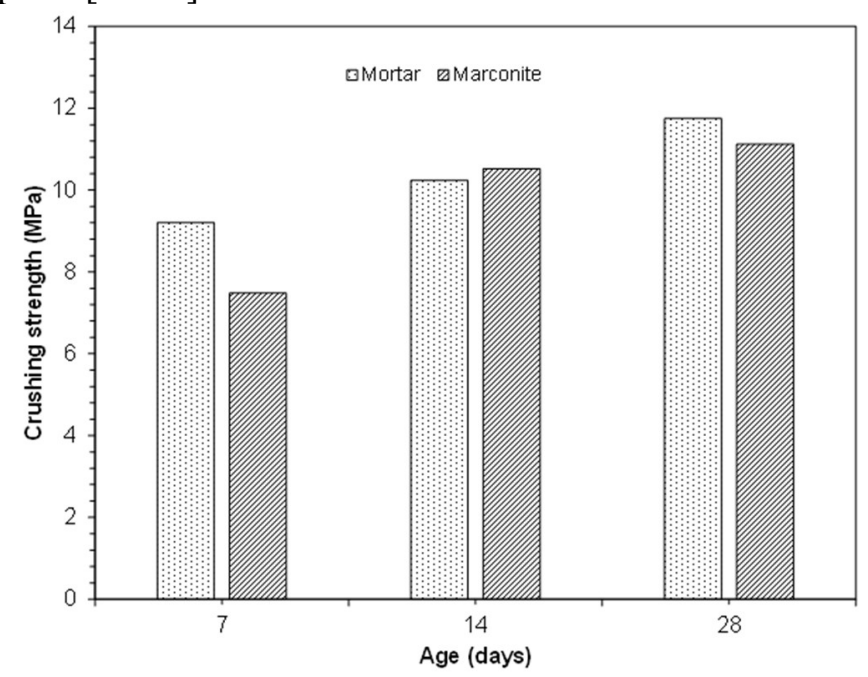

Fig. 5. Crushing strength of aggregate with mortar and Marconite

\section{CONCLUSION}

In this paper, conductive aggregates was developed by incorporating with Marconite. Marconite was incorporated into the aggregates as conductive component during manufacturing process. OPC and sand were used as main 
materials in this study to prepare aggregates. Electrical resistivity, water absorption and crushing strength were investigated in aggregated form by adding carbon-based. It can be concluded that, incorporation of Marconite as newly developed conductive aggregate could improved the electrical resistivity up to $39.2 \Omega . \mathrm{m}$. This value is significantly lower than the use of cement and sand alone. In addition, water absorption of Marconite aggregate is higher and would enchance the resistivity further under wet conditions. However, incorporating Marconite produced lower crushing strength compared to mortar. Nevertheless, this aspect did not hinders the use of Marconite aggregate as alternative material for grounding applications.

\section{ACKNOWLEDGEMENTS}

This project was fully funded by Universiti Malaysia Pahang and the Ministry of Education under fundamental research scheme FRGS/1/2017/TK05/UMP/02/2 (RDU 170133) and RDU 170343.

\section{REFERENCES}

1. Liu, Y, Zitnik, M and Thottappillil, R 2001. An improved transmission-line model of grounding system, IEEE Transactions on Electromagnetic Compatibility, 43(3), pp. 348-355. doi: 10.1109/15.942606.

2. Hasni, NAM, Abd-Rahman, R, Ahmad, H, Jamail, NAM, Kamaruddin, MS and Ridzwan, SS 2017. Investigation of Potential Grounding Compound for Portable Applications. International Journal of Electrical and Computer Engineering, 7(6), 3140.

3. Fukue, M, Minato, T, Horibe, H and Taya, N 1999. The micro-structures of clay given by resistivity measurements, Engineering Geology, 54(1-2), pp. 43-53. doi: 10.1016/S0013-7952(99)00060-5.

4. Dale, R, Boling, $P, E R I C O \AA$ and Salon, $O$ 2017. Requirements for earthing enhancement compounds, 6(2), p. 103.

5. Gomes, C, Lalitha, C and Priyadarshanee, C 2010. Improvement of earthing systems with backfill materials, 2010 30th International Conference on Lightning Protection, ICLP 2010, pp. 1-9. doi: 10.1109/ICLP.2010.7845822.

6. Chung, DDL 2009. Electrically conductive cement-based materials, Advances in Cement Research, 16(4), pp. 167-176. doi: 10.1680/adcr.2004.16.4.167.

7. Wu, J, Liu, J and Yang, F 2015. Three-phase composite conductive concrete for pavement deicing, Construction and Building Materials. Elsevier Ltd, 75, pp. 129-135. doi: 10.1016/j.conbuildmat.2014.11.004.

8. Zhang, J, Xu, L and Zhao, Q 2017. Investigation of carbon fillers modified 
electrically conductive concrete as grounding electrodes for transmission towers : Computational model and case study, Construction and Building Materials. Elsevier Ltd, 145, pp. 347-353. doi: 10.1016/j.conbuildmat.2017.03.223.

9. Zhang, D, Le, H, Yan, X, Yuan, T and Li, J 2014. Preparation of steel fiber/graphite conductive concrete for grounding in substation, ICHVE 2014 - 2014 International Conference on High Voltage Engineering and Application, pp. 2-5. doi: 10.1109/ICHVE.2014.7035490.

10. Wang, D, Wang, Q and Huang, Z 2019. Investigation on the poor fluidity of electrically conductive cement-graphite paste: Experiment and simulation, Materials and Design. The Authors, 169, p. 107679. doi: 10.1016/j.matdes.2019.107679.

11. Lee, HS, Kwon, SJ, Karthick, S, Saraswathy, V and Muralidharan, S 2017. Studies on the development of activated binary clay and corrosion monitoring using embedded sensor, Arabian Journal of Chemistry. King Saud University. doi: 10.1016/j.arabjc.2017.07.003.

12. Hassan, G 1996. Electrical Energy. In: Building Services. Macmillan Building and Surveying Series. Palgrave, London.

13. Nixon J, Lingner G, Bergin E 2019. Specification and Selection of Main Components for Air-Insulated Substations. In: Krieg T., Finn J. (eds) Substations. CIGRE Green Books. Springer, Cham.

14. Chen, B, Li, B, Gao, Y, Ling, TC, Lu, Z and Li, Z 2017. Investigation on electrically conductive aggregates produced by incorporating carbon fiber and carbon black, Construction and Building Materials, 144, pp. 106-114. doi: 10.1016/j.conbuildmat.2017, 144, pp. 106-114. doi: 10.1016/j.conbuildmat.2017.03.168.

15. Presuel-Moreno, F, Wu YY and Liu Y 2013. Effect of curing regime on concrete resistivity and aging factor over time Construction and Building Materials, 48, 874-882.

16. González-Corrochano, B, Alonso-Azcárate, J and Rodas, M 2014. Effect of prefiring and firing dwell times on the properties of artificial lightweight aggregates, Construction and Building Materials, 53, pp. 91-101. doi: 10.1016/j.conbuildmat.2013.11.099.

17. Tuan, BLA, Hwang, CL, Lin, KL, Chen, YY and Young, MP 2013. Development of lightweight aggregate from sewage sludge and waste glass powder for concrete, Construction and Building Materials. Elsevier Ltd, 47, pp. 334-339. doi: 10.1016/j.conbuildmat.2013.05.039.

18. Ahmed, H, Bogas, JA. and Guedes, M 2018. Mechanical behaviour and transport properties and cementitious composites reinforced with carbon nanotubes, Journal of Materials in Civil Engineering, 30(10), 04018257. 
19. Hung, MF and Hwang, CL 2007. Study of fine sediments for making lightweight aggregate, Waste Manage Res, 25(5). 449-456.

20. Baharudin, F, Tadza, MYM, Imran, SNM and Jani, J 2018. Removal of Iron and Manganese in Groundwater using Natural Biosorbent, IOP Conference Series: Earth and Environmental Science, 140(1). doi: 10.1088/17551315/140/1/012046.

21. Tadza, MYM, and Baharudin, F 2017. Treatment Efficiency and Compressibility Behaviour of Soil Modified with Powdered Activated Carbon, International Journal, 12(33), 122-126.

22. Shariq, M, Prasad, J and Ahuja, AK 2008. Strength development of cement mortar and concrete incorporating GGBFS, Asian Journal of Civil Engineering (Building and Housing), 9(1), 61-74.

23. Fakhfakh, E, Hajjaji, W, Medhioub, M, Rocha, F, Lopez-Galindo, A, Setti, M, Kooli, F, Zargouni, F and Jamoussi, F 2007. Effects of sand addition on production of lightweight aggregates from Tunisian smectite-rich clayey rocks, Applied Clay Science, 35(3-4), 228-237.

24. Huang, SC, Chang, FC, Lo, SL, Lee, MY, Wang, CF and Lin, JD 2007. Production of lightweight aggregates from mining residues, heavy metal sludge, and incinerator fly ash, Journal of Hazardous Materials, 144(1-2), 5258.

25. IEEE Std. 142 (2007) Grounding of Industrial and Commercial Power Systems. doi: 10.2106/JBJS.J.00277.

26. Tadza, MM, Mohamad, D, Tripathy, S, Rahman, RA and Ismail, MAM 2019. Bentonite and marconite for electrical grounding applications from geotechnical engineering perspective. In AIP Conference Proceedings 2129(1), 020078. AIP Publishing.

Editor received the manuscript: 12.08.2019 